Bol. Acad. peru. leng. 62. 2017 (189-204)

\title{
La poesía de Abraham Valdelomar
}

\section{The poetry of Abraham Valdelomar}

\author{
RicARDo SILVA-SANTISTEBAN
}

Academia Peruana de la Lengua

\section{Resumen:}

La poesía de Abraham Valdelomar es poco estudiada en comparación con sus cuentos. Por tal razón, en este artículo explico la importancia que tiene esta para orientar el horizonte de la poesía peruana. Se analizan «Luna Park» y «Nocturno», poemas que no apelan al alarde verbal del modernismo sino que con su simplicidad nos conmueven por el sentimiento genuino que transmiten. En suma, son poemas que trazan la senda que debía seguir la poesía peruana del futuro.

\section{Abstract:}

Abraham Valdelomar poetry is little studied in comparison to his stories. For this reason, this paper explains the importance his poetry has to guide the horizon of the Peruvian poetry. "Luna Park" and "Nocturno" are analyzed. These poems that do not invite verbal boast of modernism but with their simplicity move us by the genuine feeling they transmit. Concisely, they are poems that draw the path that Peruvian poetry should follow in the future. 
Palabras clave: Abraham Valdelomar, poesía peruana, modernismo, posmodernismo.

Keywords: Abraham Valdelomar, Peruvian poetry, Modernism, Postmodernism.

Recibido: 15/07/2017

Aceptado: 20/08/2017

Abraham Valdelomar nació en Ica en 1888 y falleció trágicamente en Ayacucho en 1919, luego de una corta pero deslumbrante carrera literaria en la que acometió todos los géneros. En Valdelomar se ha privilegiado al admirable cuentista que es con detrimento del poeta, el ensayista y el dramaturgo en una obra vasta y desigual en que se destacan dos tonos nítidamente diferenciados: uno exotista y artificial y otro en que se respira y palpa el ambiente de su aldea natal. Se trata, pues, de dos facetas del mismo escritor que coexistieron a lo largo de su vida: la esteticista, que podemos asimilar al modernismo, y la moderna, que podemos asimilar al posmodernismo. Una vez madurada su expresión, no continúa en Valdelomar la evolución de su escritura, sino que ambos aspectos, esteticista y moderno, se dan al mismo tiempo. Por supuesto que esto a veces no puede observarse en forma muy clara, pero después de la creación de los cuentos criollos, es decir, de «El Caballero Carmelo», «Los ojos de Judas» y «El vuelo de los cóndores», tenemos la composición de algunos de los cuentos incaicos de Los hijos del Sol y de los cuentos chinos, los primeros de índole nítidamente esteticista. 
Bien se ve por estas afirmaciones que el término modernista con que se designa la corriente literaria que reaccionó contra la pedestre y retórica poesía castellana -tanto española como hispanoamericanade la segunda mitad del siglo XIX, es el que vemos colindante o perteneciente al esteticismo. En el ámbito hispánico el esteticismo sobrevive o se transmuta en el llamado movimiento modernista. Bien visto, este movimiento posee una figura dominante y absoluta en Rubén Darío, pero Darío que, aparentemente, procede de los simbolistas, heredó y reflejó también, sobre todo, la estética parnasiana. El mundo de Darío se encuentra, por desgracia, repleto de los oropeles y de la pacotilla de la belle époque:

de lo cual es consecuencia que elaborara sus versos a base de objetos y cosas que estimaba previamente «poéticos»: rosas, cisnes, champaña, estrellas, pavos reales, malaquita, princesas, perlas, marquesas, etc. Sus versos son un inventario de todos esos artefactos poéticos ad-hoc ${ }^{1}$.

La poesía, a menudo o casi siempre, exquisita de Rubén Darío tenía que penetrar también el ámbito de las letras peruanas, y ahí están para testimoniarlo las obras poéticas de José María Eguren, Abraham Valdelomar y César Vallejo, para solo mencionar a tres de los poetas peruanos más destacados.

En lo que se refiere a la poesía de Valdelomar puede observarse un caso de superación y evolución más notorio que en el de los otros géneros literarios que

1 Luis Cernuda. Poesía y literatura I y II. Barcelona, Editorial Seix Barral, 1971, pág. 270. 
frecuentó. Los primeros poemas de Valdelomar están penetrados de un modernismo pelo en pecho que raya en lo huachafo y adocenado. Poemas como «La ofrenda de Odhar» o «En las ruinas de un monasterio» son el ejemplo más notorio de esta faceta ornamental y decorativa de la poesía de Valdelomar en la que funcionan a la perfección los «artefactos poéticos ad-hoc» citados por Luis Cernuda.

Abraham Valdelomar no parece haber tenido nunca en mente la escritura de un libro de poemas. Como la mayor parte de su escritura, sus textos hay que agruparlos por su proximidad y su continuidad temática. En el caso de sus poemas, su escritura fue tan espontánea como su publicación. En vida, Valdelomar reunió una sola vez un pequeño conjunto de sus versos en una antología colectiva titulada Las voces múltiples (1916), libro que podemos considerar como una manifestación de carácter generacional. Lo único que puede afirmarse es que la escritura de sus poemas fue esporádica a través de los años, con creaciones de carácter disímil, pero que siempre acompañaron su carrera de escritor.

Esto quiere decir que la escritura de los poemas de Valdelomar constituyen un conjunto de poemas ocasionales. Es decir, que su composición no se estructura en una unidad o unidades, como todos los poemas que aprendieron a componer sus conjuntos temáticos a partir de Les Fleurs du mal de Charles Baudelaire. De él aprendieron los poetas americanos a estructurar sus libros. Piénsese en el Rubén Darío de Prosas profanas o en el César Vallejo de Los heraldos negros. 
En el caso de Abraham Valdelomar, su producción poética la constituyen poemas sueltos. La creación poética de Valdelomar, restringida a los momentos de inspiración y de espontaneidad de escritura, posee, sin embargo, dentro de la poesía peruana contemporánea, más que un carácter de tipo fundacional, uno de tipo direccional. La poesía dominante de la época era la de la corriente modernista. Valdelomar, que había compartido sus ideales en determinado momento de su acercamiento a ella, en sus inicios literarios, supo imprimir una dirección a su creación poética distinta implosionando lo artificial del movimiento hacia una escritura que hasta podría considerarse pedestre si esta no estuviera sustentada por un legítimo y genuino sentimiento que sostiene sus poemas más allá de su forma y contenido.

Como poeta, los textos más valiosos de Valdelomar son aquellos en los que su alma sencilla se enciende con los colores patinados del cielo costeño y se emociona con el crepúsculo azafranado. Lo que más impresiona en Valdelomar es esa ternura infantil de una poesía que esconde su laboriosidad, con rimas pobres, períodos sintácticos aparentemente pedestres y encabalgamientos sin habilidad. Pero, en realidad, la poesía en verso de Valdelomar, que tuvo su arranque en el modernismo más libresco y artificial, intenta horadar el lujo verbal característico de esta corriente y abandonar su rotundidad y colorido. Valdelomar busca un tono coloquial que, cuando no lo penetra el prosaísmo por carencia de imaginación, logra las notas de una verdadera y nueva poesía. 
Los primeros poemas de Valdelomar valen muy poco. La dependencia e imitación de otros modelos modernistas afloran en todos ellos. Nuestro poeta no hacía sino expresarse, como lo hacían sus coetáneos, mediante la visión de mundos pretéritos esfumados que hacían la delicia de los lectores de la época. Poemas que se encuentran en los predios de "Sonatina» de Rubén Darío. Por ejemplo «Ha vivido mi alma...»:

Ha vivido mi alma en las Edades viejas en un guerrero heroico y un galán trovador, $y$ en gentiles mancebos de enroscadas guedejas enamorada siempre de una prohibición. Mi alma fue de Tartufo, de un ídolo pagano, de un impúber de Lesbia, de un fauno y de un bufón; vivió dentro del cuerpo de un gladiador romano, y en el cuerpo caduco de un viejo Faraón.

Ha vivido en las aguas y ha vivido en las rosas, ha vivido en los hombres y ha vivido en las cosas, buscando siempre amor.

Irá hacia un país lejano de sátiros traviesos y de labios de sangre, que conviertan en besos las cosas que no son...

Y vivirá mi alma en las cosas futuras sintiendo las saetas de nuevas desventuras, en una larga, triste, cruel peregrinación...

Este tema, ya se sabe, fue utilizado en poemas ejemplares de Gérard de Nerval y de Charles Baudelaire, pero luego fue muy imitado por los poetas modernistas a quienes, seguramente, Valdelomar imitaba. Se trata, pues, de los poemas de un poeta que recién empieza. Veamos, por ejemplo, el poema «La ofrenda de Odhar...»: 
Caminaba el anda

sobre doce nubios de pieles brillantes

hacia Samarcanda.

Regado de flores - amapolas rojas-

se abría el camino que iba a la mezquita.

Los esclavos negros pisaban las hojas

y sus albornoces manchaban de blanco la ruta bendita.

En el anda iba la reina de Oriente

que se adormitaba pálida y silente

bajo las ojivas de sus alfeizares

mimada por suaves abanicos indios

y por enervantes antimacazares.

¡Oh la reina mora, la reina brillante!

A Odhar, que era un niño, su primer amante,

a cambio de un beso le pidió un collar

$\mathrm{y}$ todos sus blancos dientes blancos marfilinos

que eran amuleto contra los destinos

galante el infante los hizo engarzar.

Fue al camino triste como sus amores

por donde pasaba con sus servidores

la reina, y, entonces, el muriente Odhar

pálido y tranquilo la esperó en las flores

y al pasar la reina, la ofreció el collar.

Sobre el blando cuerpo del joven amante

pasaron los nubios el anda triunfante.

Entre nubes rosas - mirra y eucalipto-

sobre las cabezas de nubios sansones

entró la graciosa princesa de Egipto

en el viejo templo de los Faraones.

Al salir del templo la reina galante

se olvidó del niño — su primer amante-

cuya boca en sangre no quiso besar

y al primer esclavo que llegó a los pálidos mármoles del templo

como una limosna le ofreció el collar.

Con los doce nubios

tristemente, el anda

se perdió en la ruta que iba a Samarcanda... 
Los grandes poetas no se encuentran exentos de la huachafería. Recordemos, por ejemplo, «Ascuas», ese lamentable poema del César Vallejo de Los heraldos negros. De ahí que adquiera más valor el camino seguido posteriormente por Valdelomar que, como aconsejaba el poeta mexicano Enrique González Martínez a otros poetas coetáneos, había que torcerle el cuello al cisne que representaba la poesía preciosista del modernismo.

En el Valdelomar escritor siempre coexistió una tendencia de contrarios que nunca pudo resolver y que se expresó en creaciones disímiles y hasta opuestas. Tal parece haber sido su experimentación en poemas de poéticas diferentes. Valdelomar no dejó de escribir otros poemas lamentables producto de su afición a la escritura decadente de la época y a su propia frivolidad, pero supo apartarse de ella en los mejores momentos con su «aldea encantada», como la llamaba, al recurrir a experiencias expresadas con audacia.

Existe, por ejemplo, un interesante poema de Valdelomar que puede considerarse a la vez un triunfo y una derrota poéticos. Se trata de «Luna Park», un poema largo que condensa su experiencia de viajero en su paso por París. Dentro del desarrollo de su poesía, «Luna Park» es interesante por una serie de motivos. En primer lugar, retoma el verso libre que había practicado escasamente en muestras anteriores que no parecen haber sido tomadas en cuenta por la crítica dentro de la evolución de la poesía peruana pese a lo madrugadores que son dentro de esta tradición. «Luna Park» fue, además, uno de los poemas preferidos por Valdelomar, como puede testificarse por su recurrente publicación a lo largo de su vida. 
La experiencia narrada en el poema se realizó seguramente en 1913 entre los días que permaneció en París antes de dirigirse a Roma para hacerse cargo del puesto que lo esperaba en la Embajada del Perú.

El poema narra su asistencia a un lugar de gran concurrencia, seguramente inevitable, entre las visitas de un turista a una ciudad importante:

En París, una noche, una dama, el Destino

y mi sudamericana curiosidad,

lleváronme hacia la maravilla

deslumbrante y sonora de Luna Park.

El auto se detuvo matemáticamente:

la fiesta había comenzado ya.

Subí tímido y serio con mi dama,

más blanca y fresca que el crisantemo de mi frac, para ver cómo se divertía

en el centro del mundo la Humanidad.

Puede observarse, en una simple lectura, que se trata de un poema narrativo-descriptivo escrito en un verso libre que parece provenir, lejanamente, de los polirritmos inventados por Manuel González Prada. La visión es la del turista, es decir, la de un personaje ajeno al mundo que recorre y que se concreta en una experiencia en que concurre la visión antagónica de civilización y barbarie resuelta en una ecuación de experiencia e ingenuidad. Paradójicamente, es el salvajismo lo que impera dentro de la civilización moderna de las que se nos muestran algunos indicios la mayoría de ellos frívolos y vacíos, el de una humanidad cansada de sí misma que no tiene ninguna cosa positiva que mostrar. El drama de la cultura radica en que la ciencia progresa a un ritmo que el hombre no puede asimilar en el espíritu, pues este 
lo hace a menor velocidad. Por desgracia, el hombre solo puede arribar al vacío por su incapacidad para colmar su evolución espiritual. Otras veces al hombre le es imposible evolucionar y tiende más bien a la involución. El tema parece haber desbordado al poeta, capaz de advertir la vacuidad de una sociedad que se encuentra en el pináculo de sí misma. El poeta, sin embargo, carece de la habilidad para desarrollar este tema en toda su dimensión dentro del poema.

«Luna Park» muestra, en su momento cenital, a un grupo de salvajes tan fuera de lugar en este «centro del mundo» frente a los ojos desengañados del yo poético.

Y en medio de la vida fugaz, que no tiene más dioses que Monsieur de Fouquières ni otro templo que el admirable de Paquin ni otra música que el tango cadencioso que en sus rítmicos pasos hace olvidar, reír, llorar, elevando sus almas a regiones de ensueño donde desaparece todo mal. Vinos, damas, cigarros, placer, tango argentino, ¿qué más?...

Bajo a los parques simétricos donde derraman su luminosidad mil lucecillas como mil ojos encendidos que no se cansan de mirar; carrouseles que giran vertiginosamente, ferias, carritos, caballos, lagunas; un bazar donde las demoiselles ofrecen monitos de goma que caminan con apostura marcial.

En un rincón hay una tribu de salvajes en donde ceban su curiosidad niños, ancianos, mujeres y soldados que oyen el raro platicar 
de aquellos primitivos que en sus cónicas chozas, indiferentes y desnudos, vienen y van.

Así, el autor ve en este grupo salvaje más bien un conjunto humano cuya pureza e inocencia hay que preservar de la agresión de una civilización fatua y estéril y el poema toma un equivocado tinte moralista mal desarrollado por Valdelomar.
Érais fuertes, ágiles, viriles, teníais una suprema libertad; vuestros ropajes eran el rayo cálido del día y en la noche la caricia lunar; vuestras aves eran vuestras, vuestra tierra lo era; no distinguíais el Bien del Mal sino por lo que os gustaba y lo que os dejaba de gustar. ¡Infelices salvajes! No más bosques ni ríos no más valles fecundos, no más asar cabritillos silvestres en las fogatas rojas ni vencer la furia del brutal elefante, ni del inquieto tigre, ni del león iracundo.

La exhortación y el lamento a los que se apela son demasiado directos en el poema y, por ello, pierden la eficacia de constituirse en una denuncia de carácter universal. Esta debió haber quedado en la mostración al lector del choque que se da entre civilización y barbarie sin tomar partido, solo haciéndolo evidente $y$, de esta forma, hacer patente la discordancia. Por eso afirmaba al comienzo de un triunfo y de un fracaso poéticos. Este poema, sin embargo, abrió una nueva senda desde el centro mismo de los ideales del modernismo al tomar la poesía de Valdelomar un nuevo camino de abandono del exotismo y la frivolidad. 
Tal tendencia puede encontrarse también en otro poema dentro de la obra de Valdelomar que ejemplifica cabalmente, con mayor inclinación, y de manera más extremada, este desapego de la estética modernista que se encuentra en las antípodas de sus primeros y artificiales poemas. Se trata de «Nocturno»:

Ya la ciudad está dormida, yo solo cruzo su silencio $\mathrm{y}$ tengo miedo que despierte al suave roce de mis pasos lentos...

La iglesia eleva sus dos torres en la oquedad honda del cielo y cruza el aire el pentagrama del poste del teléfono.

Pide limosna, lamentable, un mendicante viejo y ciego y habla de Dios y dice: ¡Hermanos!

$\mathrm{y}$ tiende al aire su sombrero.

Pasa un borracho hinchado el rostro, echa hacia mí su aliento fétido, alza los brazos y gritando:

— ¡Viva el Perú! se cae al suelo.

La luz de un arco parpadea, chocan sobre ella los insectos, cambia a mis pasos la quebrada rara silueta de los techos.

Duerme un cansado caminante en el dintel amplio del templo y allí en la esquina, junto a un poste, con gravedad se mea un perro.

Ya la ciudad está dormida, yo solo cruzo su silencio 
y me parece que alguien sigue

mis pasos a lo lejos...

[...]

Ya la ciudad está dormida

y sólo cruza su silencio

el ruido que hace la pesada

negra carroza de los muertos...

Valdelomar busca en este poema un tema deliberadamente prosaico y yo diría que transgresor para los criterios de la poética modernista y esteticista de la época. No diremos que alcanza el vigor de la modernidad al intentar mostrarnos la belleza de lo vulgar y repugnante. Creo, más bien, que Valdelomar lo que intenta es, en primer lugar, mostrar mediante un arte realista, en el sentido amplio del término, una visión alucinada y alucinante de la ciudad de Lima. Pero quizá exista también la intención del poeta de irritar a sus lectores con un poema deliberadamente pedestre y extraño para el gusto del momento. Si «Nocturno» no constituye un poema excepcional, quizá se deba al tono de meditación artificial que poseen algunas de sus estrofas que lo alargan innecesariamente contra el carácter inevitable que estas deberían haber tenido. Pero esto no lo hace menos valioso porque, a pesar de todo, Valdelomar estaba logrando las notas de una nueva poesía.

Largo, pues, fue el camino recorrido por Valdelomar para alcanzar la escritura de sus mejores poemas: luego de su aceptación juvenil de una corriente apabullante como la modernista que aportaba, qué duda cabe, un cambio notable respecto de la poesía precedente. Sin embargo, sus excesos verbales debilitaron muy pronto 
los hallazgos de esta nueva expresión que se dilató en un adocenamiento improductivo. Valdelomar, que ya había escrito sus extraordinarios Cuentos criollos, optó, entonces, repito, por un rápido desapego del exotismo y compuso una breve cosecha de poemas dedicados en gran parte a experiencias vividas en su «aldea encantada» y escribió sus creaciones más destacadas en el ámbito poético. Veamos dos de ellas:

\section{EL ÁRBOL DEL CEMENTERIO}

No en la tranquilidad de la arboleda que ofrece sombra fresca y regalada al remanso, al pastor y la manada y que paisaje bíblico remeda;

no el suspiro de la ola cuando rueda a morir en la playa desolada, ni el caer de la tarde en la callada fronda que al ave taciturna hospeda;

dieron a mi niñez ésta en que vivo sed de misterio, torturante y honda, fue del panteón el árbol pensativo

cuyas ramas inerte sombra daban a la inclinada cruz; y en cuya fronda las torvas aves trágicas, graznaban...

En este poema, Valdelomar utiliza versos endecasílabos y su poema aúna no solo sinceridad y empatía con un paisaje vivido, sino también un tono justo y límpido en un metro tradicional de la expresión castellana. En «La casa familiar», otro de sus grandes poemas, Valdelomar retoma el verso alejandrino que fue uno de los preferidos de los poetas modernistas. 
Ya la casa está muerta. Ya no es la misma casa. El jardín florecido se extinguió... A la desierta alcoba ya no sube, escaladora experta, la vid, de frescos pámpanos, en racimos escasa.

Ya el asno con la alfalfa florecida no pasa, ni el viejo panadero se detiene a la puerta, ni platican los padres... ¡Ya la casa está muerta, ya no hay voces hermanas, ya no es la misma casa!

Humedad. Muros rotos. Un acre olor de olvido. Hieráticas, las viejas blancas aves marinas se posan en la triste morada solitaria.

Y sobre los escombros del hogar extinguido el ñorbo abre en el aire su corona de espinas, ¡su corona de espinas, perfumada y precaria!

Se trata aquí de un retorno a «la aldea encantada», de su juventud y de sus sueños. Probablemente «La casa familiar» sea uno de los mejores poemas de Valdelomar por constituir un producto destilado en el que se conjugan paisaje, emoción, sentimiento y una expresión carente de los oropeles de los primeros poemas. Sabemos, por una carta remitida a Alejandro Parró en 1916, que este poema se escribió cuando Valdelomar visitó su antigua morada. El sentimiento brotó y se expresó con la reproducción plástica a la que sustenta una emoción contenida.

Puede comprobarse que aquí la poesía se abre un ancho camino sin necesidad de oropeles. La sencillez prima en estos cuadros hogareños e intimistas que no necesitan ningún alarde verbal, como no sea el de su 
propia simplicidad. Destaca la sinceridad y nos conmueven por su sentimiento genuino. Dentro de esta nota aldeana y campesina de Valdelomar podríamos citar también «El hermano ausente en la cena de Pascua» ${ }^{2}$ y «Tristitia», poemas que demuestran la decantación de su expresión que ofrece en ellos sus mejores versos.

Creo que con los poemas citados le mostró a Vallejo cuál debía ser el camino de la poesía peruana en lo futuro. Así, este escritor fallecido demasiado joven es no solo importante por ser el autor de algunos poemas inevitables de la poesía peruana del siglo XX, que conjugan no solo emoción y expresividad genuinas, sino también por trazar la senda que debía seguir la poesía peruana del futuro en una dirección diferente de la de José María Eguren.

2 Ignoro si Valdelomar leyó el poema «El viajero» de Soledades de Antonio Machado que trata, a diferencia del poeta peruano, del retorno del hermano ausente. Podría existir una conexión por inversión del tema. De todas formas, en el cuento maestro de Valdelomar «El Caballero Carmelo», se explota, en el primer capítulo, el tema del retorno del hermano viajero luego de muchos años. Con toda probabilidad, se trata de una experiencia compartida entre ambos poetas. 